\title{
Highly Dispersed Gold Particles on Polyaniline - A New Nanocatalyst for Selective Hydrogenation
}

\author{
F. Klasovsky ${ }^{1}$, M. Steffan ${ }^{1}$, J. Arras ${ }^{1}$, J. Radnik $^{2}$ and P. Claus ${ }^{*}, 1$ \\ ${ }^{\text {I}}$ Department of Chemistry, Darmstadt University of Technology, Germany \\ ${ }^{2}$ Leibniz Institute of Catalysis, Berlin, Germany
}

\begin{abstract}
A new nanocatalyst which comprises gold particles (average size $=(2.5 \pm 1.3) \mathrm{nm}$ ) supported on intrinsically conductive polyaniline (PANI) was prepared via a sol-method. This Au/PANI catalyst was used for the first time in hydrogenation of the $\alpha, \beta$-unsaturated aldehyde citral exhibiting high activity (93\% conversion) and selectivity (76\%) towards the products of $\mathrm{C}=\mathrm{O}$ group hydrogenation, geraniol and nerol, whereas the selectivity towards the product of the hydrogenation of the conjugated $\mathrm{C}=\mathrm{C}$ bond (citronellal) is rather low $(23 \%)$.
\end{abstract}

\section{INTRODUCTION}

Since the development of Ziegler-Natta catalysts, the synthesis of conjugated polymers marked a challenge in polymer synthesis as these materials were expected to posess unique electronic, optical and/or magnetic properties, owing to the extended $\pi$-electron system. Indeed, polyacetylene, first synthesized by the group of Shirakawa in a highpressure approach [1], exhibits a conductivity of $10^{-5} \mathrm{~S} / \mathrm{cm}$ focused on composites with metal nanoparticles. Au/PANI composites with $20 \mathrm{~nm}$ sized gold nanoparticles were produced by Kleinermanns et al. [5] in a surfactant-based polymerization approach. Though interaction between gold and PANI seems to be weak, the composite exhibits a twofold higher conductivity than the bare polymer. A detailed investigation on the formation of Au/PANI composites was reported by Hatchett et al. [6] who identified aniline oligomers as key intermediates during aniline oxidation with $\mathrm{AuCl}_{4}{ }^{-}$.

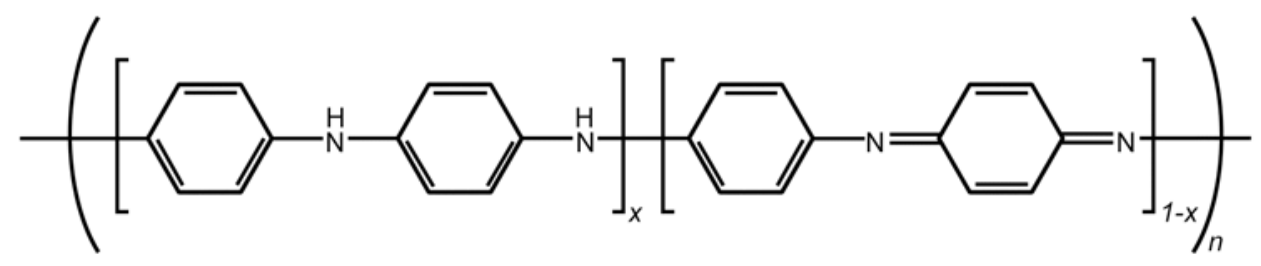

Scheme 1. General structure of polyaniline (PANI).

which upon doping with iodine could be increased tremendously by ten orders of magnitude. Intrinsically conducting polymers were since investigated in detail, and in 2000 the nobel prize was dedicated to Shirakawa, Heeger and MacDiarmid for their pioneering works [2].

Among the group of conducting polymers, polyaniline (PANI) can be obtained either electrochemically or by chemically induced oxidative polymerization [3]. Applying this rather simple beaker chemistry results in formation of a polymer containing subunits of different nitrogen bonding states. Accordingly, leucoemeraldine consists entirely of benzenoid subunits (Scheme 1, $\mathrm{x}=1$ ) whereas the fully oxidized pernigraniline $(x=0)$ is built of quinonoid rings; among other intermediate structures, the half-oxidized form $(\mathrm{x}=0.5)$ is designated as emeraldine base.

Because of its high thermal and mechanical stability, polyaniline is hitherto utilized for corrosion protection, sensing and electronic devices [4], however, interest is also

*Address correspondence to this author at the Department of Chemistry, Darmstadt University of Technology, Germany;

E-mail: claus@ct.chemie.tu-darmstadt.de
Obtainable metal loadings were high, however, the gold particle size of $\sim 1 \mu \mathrm{m}$ is not suited for catalytic application. Much smaller particles $(\sim 1.9 \mathrm{~nm})$ were obtained by lowtemperature aniline oxidation with $\mathrm{AuCl}_{4}{ }^{-}$as reported by Kaner et al. [7]. XPS and Raman spectroscopy unveiled a particle size independent charge transfer from emeraldine to gold which could be suppressed after liquid-phase reduction of the composite. However, it must be noted that applications of metal/PANI composites in chemical catalysis are scarce. While Sobczak et al. [8] and the group of Drelinkiewicz [9] reported on PANI based Pt and Pd catalysts for the hydrogenation of alkynes and 2-ethylanthraquinone, respectively, oxidation reactions were investigated for glucose with supported Au catalysts (based on ion exchanger) by Chattopadhyay [10] and for alcohols with PANI supported Mo and V complexes by Punniyamurthy [11].

Although the application of nanoparticulate gold as unusual hydrogenation catalyst was up to now confined to rather classical, i.e. oxidic support materials [12], polyaniline supported gold has not been used - to the best of our knowledge - as hydrogenation catalyst. 


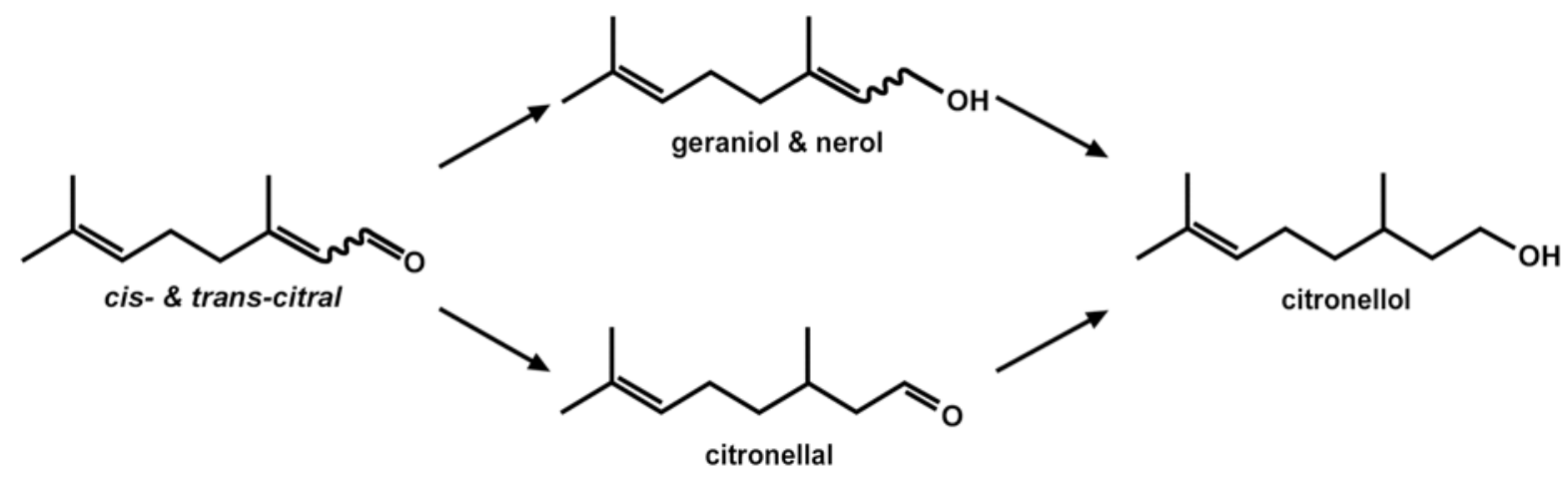

Scheme 2. Simplified reaction network of citral hydrogenation.

Therefore, in this work, the first goal was to introduce the approach of colloidal metal particles (synthesized via the sol method), enabling well-defined preformed gold particles, for immobilization onto polyaniline. After characterizing the obtained Au/PANI materials by physico-chemical methods (ICP-OES, TEM, XPS, XRD) the second goal was to evaluate their catalytic properties in a hydrogenation reaction. For that purpose the $\alpha, \beta$-unsaturated aldehyde citral (3,7dimethyl-2,6-octadienal) was chosen as substrate which has three functionalities $(\mathrm{C}=\mathrm{O}$ group, conjugated $\mathrm{C}=\mathrm{C}$ bond, isolated $\mathrm{C}=\mathrm{C}$ bond) enabling to study how the PANI supported gold affects the intramolecular selectivity.

\section{EXPERIMENTAL}

The preparation of the Au/PANI catalysts started with synthesis of a preformed gold sol following a procedure applied for carbon-supported Au catalysts which has been described elsewhere [13]. Then, in the present work, the gold sol was allowed to immobilize onto the PANI support (Aldrich, emeraldine base, $\mathrm{M}_{\mathrm{w}}=65.000$ ). Briefly, a solution of $\mathrm{HAuCl}_{4}$ (Alfa Aesar) was added to an aqueous mixture of tetrakis-(hydroxymethyl)-phosphonium chloride (THPC, Merck) and $0.2 \mathrm{M} \mathrm{NaOH}$. The immediately formed deep-red gold sol was stirred for one hour and subsequently adsorbed on the support (suspended in water beforehand) by stirring for another 24 hours. After isolation via filtration and washing with water, Au/PANI-1 (Table 1) was dried $\left(110^{\circ} \mathrm{C}\right)$ without further treatment. Au/PANI-2 was synthesized as described above but with a different metal loading, whereas Au/PANI-3 was additionally heat treated in $\mathrm{N}_{2}$ and $\mathrm{H}_{2}$ at $350^{\circ} \mathrm{C}$ for $3 \mathrm{~h}$.

The gold content of the materials was analyzed by ICPOES using a Perkin Elmer Optima 3000XL used after dissolving the materials in a mixture of $\mathrm{HF} / \mathrm{HNO}_{3}$ by means of a MDS-2000 microwave unit (CEM). The size of gold particles and their morphology was determined by HighResolution Transmission Electron Microscopy, HRTEM (JEOL JEM-3010, $300 \mathrm{kV}$ ). The catalysts were further characterized by X-ray Photoelectron Spectroscopy (XPS). Data were collected by using a VG ESCALAB 220 iXL system (VG Scientific) with an monochromated $\mathrm{Mg} \mathrm{K}_{\alpha}$ excitation source $(1253.6 \mathrm{eV})$. The spectra were referenced to the $\mathrm{C} 1 \mathrm{~s}$ peak (binding energy $=284.8 \mathrm{eV}$ ). The peak positions could be determined with a precision of $\pm 0.1 \mathrm{eV}$.

Catalytic experiments (liquid phase hydrogenation of citral) were carried out in a batch reactor (Parr Co.) with a chemically-resistant Teflon-vessel at $160^{\circ} \mathrm{C}$ and a hydrogen pressure of 7.0 MPa with $n$-hexane as solvent and $n$ tetradecane as internal standard. Samples were taken periodically and analyzed with off-line GC (DB-WAX capillary column $30 \mathrm{~m}, 0.25$ i.d.).

\section{RESULTS AND DISCUSSION}

ICP analyses prove nearly complete metal adsorption for all prepared catalysts. HRTEM investigation of the Au/PANI catalysts reveals a neat homogeneous distribution of the preformed gold nanoparticles on the support. Particle sizes are highly dispersed with a mean diameter of 2-3 $\mathrm{nm}$ (for the untreated catalysts), and the majority of them turned out to be facetted, crystalline multiply twinned particles (MTPs, Fig. 1). From both characterization methods applied it can be concluded that the immobilization of preformed gold particles is not only a suitable tool for preparing oxide or carbon supported catalysts but also gold particles of hitherto unknown high dispersion onto polyaniline.

XRD analysis reveals peak broadening according to the very small gold particle size estimated by HRTEM, however, the particle sizes estimated by using the Scherrer equation are in good agreement $(3$ and $12 \mathrm{~nm}$, for Au/PANI-2 and $\mathrm{Au} / \mathrm{PANI}-3$, respectively) with those from TEM analysis.

As could be confirmed by XPS measurements, gold was deposited on the PANI support in metallic state (binding energy, $\left.\mathrm{BE}: \mathrm{Au} 4 \mathrm{~d}_{5 / 2}=335.0 \mathrm{eV}, \mathrm{Au} 4 \mathrm{f}_{7 / 2}=84.7 \mathrm{eV}\right)$. The difference between the latter value and the $\mathrm{BE}$ of $84.0 \mathrm{eV}$ for bulk gold $[14,15]$ is attributed to the very small particle size according to the observed increase of $\mathrm{BE}$ with decreasing gold particle size [16]. The $\mathrm{N}$ 1s core-level spectrum in the Au/PANI samples exhibits the presence of a peak at 398.8 $\mathrm{eV}$ which is an intermediate value between $398.0 \mathrm{eV}$ and $399.5 \mathrm{eV}$ attributed to the $-\mathrm{N}=$ group and amine nitrogen ($\mathrm{NH}-$ ), respectively [17]. Pretreatment of $\mathrm{Au} / \mathrm{PANI}$ in $\mathrm{H}_{2}$ shifted the $\mathrm{N} 1 \mathrm{~s}$ binding energy to $399.5 \mathrm{eV}$ indicating the presence of the leucoemeraldine form of PANI (i.e. $x=1$ in Scheme 1).

The dependence of citral conversion on time and the corresponding selectivity-conversion plot of Au/PANI-2 are shown in Fig. 2 and the catalytic results of all catalysts are summarized in Table 1. The developed Au/PANI system, used for the first time as hydrogenation catalyst for an $\alpha, \beta$ unsaturated compound, is highly active (up to $93 \%$ conversion, Au/PANI-2). For all catalysts the selectivities to the desired unsaturated alcohols geraniol and nerol are high up 

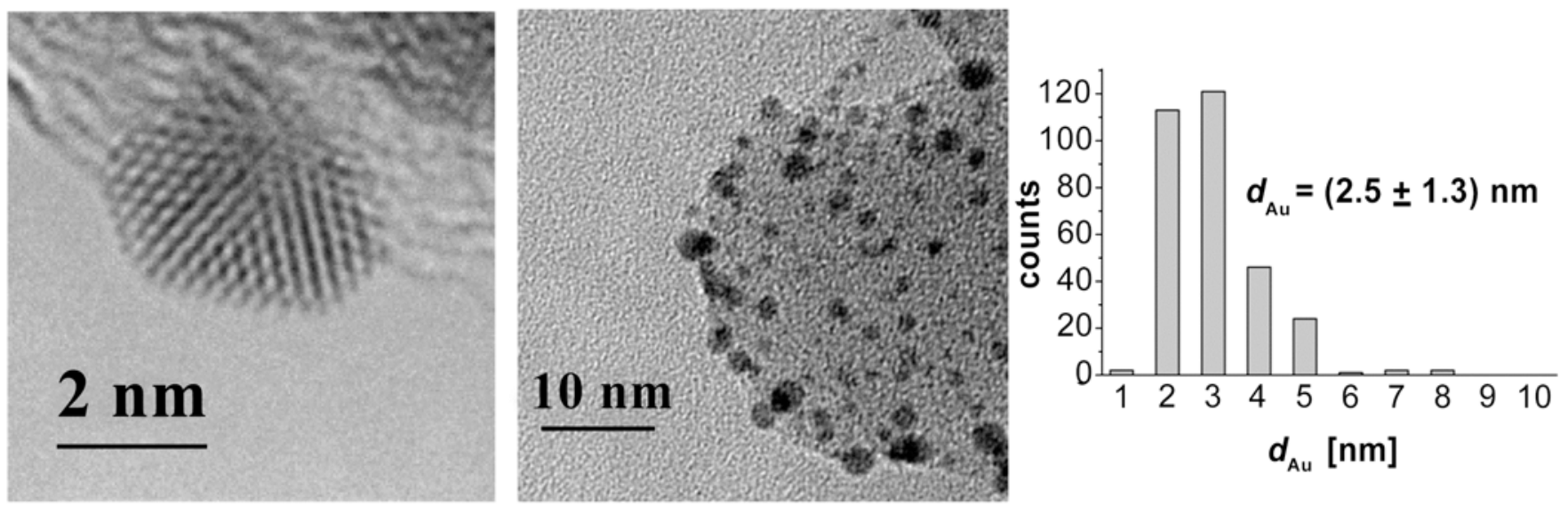

Fig. (1). HRTEM detail (left) and survey micrograph (middle) of Au/PANI-2; (right) particle size distribution.

to $76 \%\left(\mathrm{X}_{\text {citral }}=30 \%\right)$. With increasing conversion levels the differences in selectivities to the unsaturated alcohols among the catalysts fit to a narrow range between $50-65 \%\left(\mathrm{X}_{\text {citral }}=\right.$ $70 \%)$.

Catalyst recycling was investigated with Au/PANI-2 (entry 2,3). Visually, no degradation of the gold coated PANI material occurred. TEM analysis of the used sample, i.e. after hydrogenation, showed that mean particle size and distribution remained unchanged $\left(\mathrm{d}_{\mathrm{Au}}=(3.1 \pm 1.2) \mathrm{nm}\right)$. Decreased selectivities with the recycled catalyst are probably due to adsorbed compounds from the first run.

It is remarkable that $\mathrm{Au} / \mathrm{PANI}$ catalysts exhibited high activities in citral hydrogenation (Table 1, Fig. 2). Based on the conversion-time curves obtained experimentally and the mean gold particle diameter, turnover-frequencies (TOF) in the range of $0.05-0.1 \mathrm{~s}^{-1}$ can be calculated assuming a closedshell particle model [18]. While Au catalysts based on classical supports like carbon are nearly inactive for citral hydrogenation, only $\mathrm{Au}$ dispersed on iron-oxy-hydroxides led to catalysts of high activities and selectivities [19]; this effect was indirectly ascribed to the promoting effect of iron which activates the $\mathrm{C}=\mathrm{O}$ group and increases the electron density of the gold nanoparticles. According to the results of the present study, PANI seems to take the role of the charge density donor, in line with the works of Kaner [7], and thus provides a suitable support for selective citral hydrogenation with gold. Electron transfer from PANI to Au allows to increase the hydridic character of the chemisorbed hydrogen and, thus, the rate of the nucleophilic addition of $\mathrm{H}^{-}$on the positively charged carbon of the $\mathrm{C}=\mathrm{O}$ group is enhanced. Chemisorption and dissociation of hydrogen is, besides chemisorption of the organic substrate, an essential first elementary step in heterogeneously catalyzed hydrogenations. It should be noted that very small gold particles, at least in the size range of the present study, are required and that their corner and edge positions dissociate the hydrogen as evidenced by a combined study of in-situ X-ray absorption spectroscopy (XAS), chemisorption and H/D exchange experiments [20].

\section{CONCLUSIONS}

A new nanocatalyst which comprises gold particles (average size $=(2.5 \pm 1.3) \mathrm{nm})$ supported on intrinsically conductive polyaniline (PANI) was prepared via a sol-method. TEM analysis showed that the morphology is characterized by facetted, crystalline multiply twinned particles (MTPs). The developed Au/PANI system, used for the first time as hydrogenation catalyst for an $\alpha, \beta$-unsaturated compound, is highly active and affords high selectivities to the desired products geraniol and nerol, even though other, partly unknown, products are formed at higher conversions. Our results offer a simple route for the synthesis of nanosized gold particles onto a conductive polymer (gold dispersion up to $50 \%$ ), which can be considered as a new class of gold catalysts exhibiting strong potential of hitherto unknown catalytic performance in hydrogenation reactions.

Table 1. Results of Citral Hydrogenation with PANI Supported Gold Catalysts $\left(\mathrm{T}=160^{\circ} \mathrm{C}, \mathrm{p}\left(\mathrm{H}_{2}\right)=70 \mathrm{bar}, \mathrm{c}_{\mathrm{o}}(\mathrm{Citral})=0.56 \mathrm{~mol} / \mathrm{L}\right.$, Solvent: $\boldsymbol{n}$-Hexane)

\begin{tabular}{|c|c|c|c|c|c|c|c|c|c|c|}
\hline \multirow{2}{*}{ Entry } & \multirow{2}{*}{ Code } & \multirow{2}{*}{$\mathrm{w}_{\mathrm{Au}}[\mathrm{wt} . \%]$} & \multirow{2}{*}{$\mathbf{d}_{\mathrm{Au}}[\mathrm{nm}]$} & \multirow{2}{*}{$\mathbf{X}_{\text {citral }}[\%]^{a}$} & \multicolumn{3}{|c|}{$\mathbf{S}^{30}[\%]^{b}$} & \multicolumn{3}{|c|}{$\mathbf{S}^{70}[\%]^{b}$} \\
\hline & & & & & $\mathbf{U O L}^{c}$ & $\mathbf{A} \mathbf{L}^{d}$ & Others $^{e}$ & $\mathbf{U O L}^{c}$ & $\mathbf{A} \mathbf{L}^{d}$ & Others $^{e}$ \\
\hline 1 & $\mathrm{Au} / \mathrm{PANI}-1$ & 4.6 & $2.9 \pm 1.9$ & 83 & 66 & 26 & 8 & 56 & 20 & 24 \\
\hline 2 & $\mathrm{Au} / \mathrm{PANI}-2$ & 6.1 & $2.5 \pm 1.3$ & 93 & 76 & 23 & 1 & 65 & 15 & 20 \\
\hline 3 & $\mathrm{Au} / \mathrm{PANI}-2 \mathrm{R}^{\mathrm{f}}$ & 6.1 & - & 86 & 57 & 14 & 29 & 51 & 10 & 39 \\
\hline 4 & $\mathrm{Au} / \mathrm{PANI}-3$ & 5.1 & $8.4 \pm 3.8$ & 70 & 64 & 9 & 27 & 57 & 7 & 36 \\
\hline
\end{tabular}

${ }^{a}$ Citral conversion after 260 min. ${ }^{b} \mathrm{~S}^{30}$ and $\mathrm{S}^{70}=$ selectivities at $30 \%$ and $70 \%$ conversion. ${ }^{c}$ Unsaturated alcohols (geraniol and nerol). ${ }^{d}$ Saturated aldehyde (citronellal). ${ }^{e}$ Citronellol and non-identified products. ${ }^{f}$ Recycling of catalyst Au/PANI-2. 

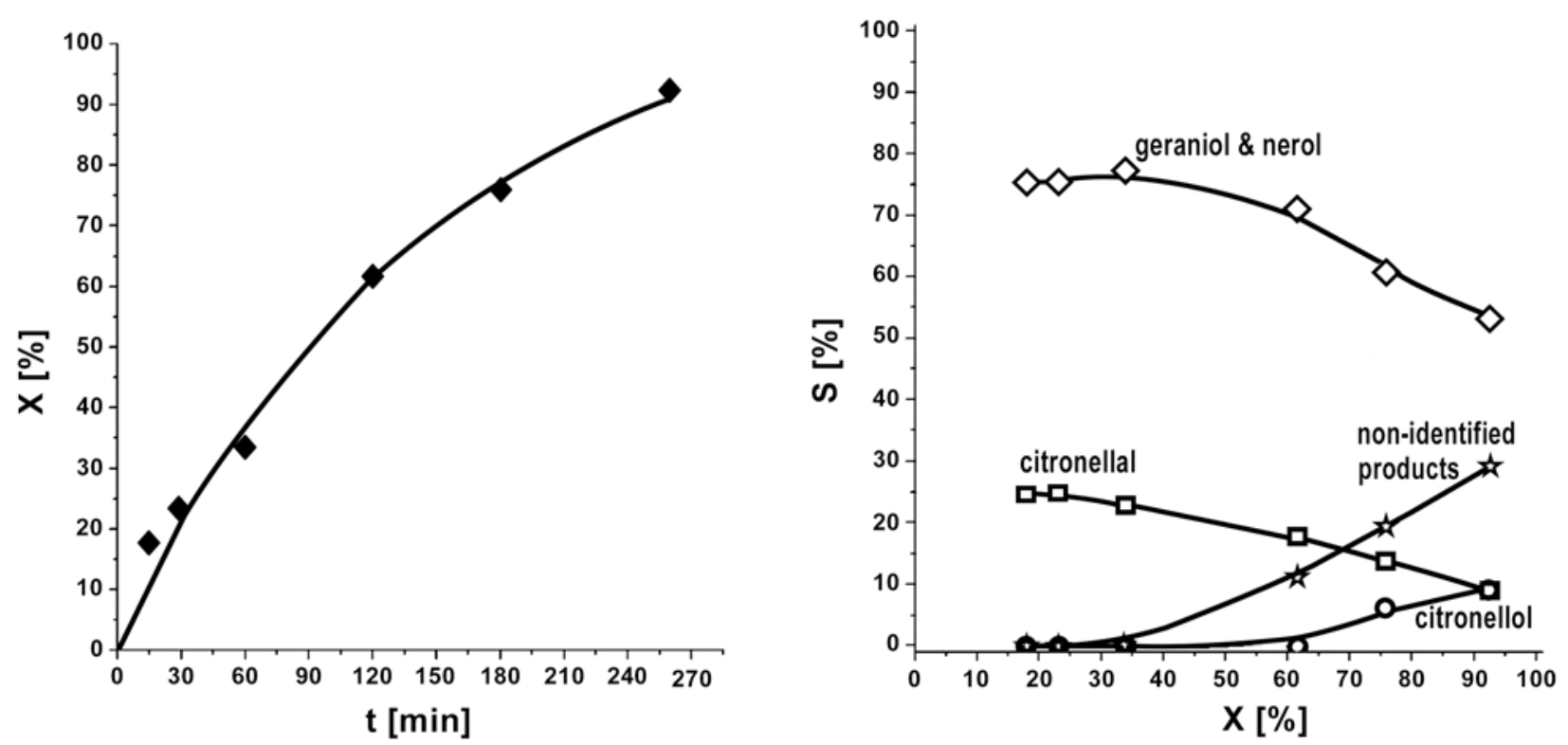

Fig. (2). Dependence of citral conversion on time (left) and selectivity-conversion plot (right) of Au/PANI-2 (see Table 1 for experimental conditions).

\section{ACKNOWLEDGEMENTS}

We are grateful to Dr K. Hofmann (Zintl-Institute, TU Darmstadt) for XRD measurements. P.C. thanks the Fonds der Chemischen Industrie.

\section{REFERENCES}

[1] Ito, T.; Shirakawa, H.; Ikeda, S. J. Polym. Sci. Chem. Ed. 1974, 12, 11.

[2] (a) Shirakawa, H. Angew. Chem. 2001, 113, 2642. (b) Mac Diarmid, A.G. Angew. Chem. 2001, 113, 2649. (c) Heeger, A.J. Angew. Chem. 2001, 113, 2660.

[3] Cao, Y.; Andreatta, A.; Heeger, A.J.; Smith, P. Polymer 1989, 30, 2305 .

[4] Mallick, K.; Witcomb, M.J.; Scurrell, M.S. Gold. Bull. 2006, 39, 166.

[5] Peng, Z.; Guo, L.; Zhang, Z.; Tesche, B.; Wilke, T.; Ogermann, D.; Hu, S.; Kleinermanns, K. Langmuir 2006, 22, 10915.

[6] Kinyanjui, J.M.; Hatchett, D.W.; Smith, J.A.; Josowicz, M. Chem. Mater. 2004, 16, 3390.

[7] Tseng, R.J.; Baker, C.O.; Shedd, B.; Huang, J.; Kaner, R.B.; Ouyang, J.; Yang, Y. Appl. Phys. Lett. 2007, 90, 053101.
[8] Sobczak J.W.; Lesiak, B.; Jablonski, A.; Kosinski, A.; Palczewska, W. Polish J. Chem. 1995, 69, 1732.

[9] Drelinkiewicz, A.; Hasik, M.; Kloc, M. J. Catal. 1999, 186, 123.

[10] Reddy, S.R.; Das, S.; Punniyamurthy, T. Tetrahedron Lett. 2004, 45,3561 .

[11] Majumdar, G.; Goswami, M.; Sarma, T.K.; Paul, A.; Chattopadhyay, A. Langmuir 2005, 21, 1663.

[12] Claus, P. Appl. Catal. A: General 2005, 291, 222.

[13] Oenal, Y.; Schimpf, S.; Claus, P. J. Catal. 2004, 223, 122.

[14] NIST X-ray Photoelectron Spectroscopy Database. http://srdata.nist.gov/xps (accessed June 06, 2000).

[15] Radnik, J.; Mohr, C.; Claus, P. Phys. Chem. Chem. Phys. 2003, 5 , 172.

[16] Anthony-Smith, J.; Josowicz, M.; Engelhard, M.; Baer, D.R.; Janata, J. Phys. Chem. Chem. Phys. 2005, 7, 3619.

[17] Choudary, B.M.; Roy, M.; Roy, S.; Lakshmi K.M.; Sreedhar, B.; Vijay, K.K. Adv. Synth. Catal. 2006, 348, 1734

[18] Montejano-Carrizales, J.M.; Aguilera-Granja, F.; Moran-Lopez, J.L. Nanostruct. Mater. 1997, 8, 269.

[19] Milone, C.; Tropeano, M.L.; Gulino, G.; Neri, G.; Ingoglia, R.; Galvagno, S. Chem. Commun. 2002, 868.

[20] Bus, E.; Miller, J.T.; van Bokhoven, J.A. J. Phys. Chem. 2005, 109 , 14581. 